\title{
Metabolic engineering of Clostridium tyrobutyricum for enhanced butyric acid production from glucose and xylose
}

Hongxin Fu, ${ }^{1,2}$ Le Yu, ${ }^{1}$ Meng Lin, ${ }^{3}$ Jufang Wang, ${ }^{4}$ Zhilong Xiu, ${ }^{2}$ Shang-Tian Yang ${ }^{1, *}$

${ }^{1}$ William G. Lowrie Department of Chemical and Biomolecular Engineering, The Ohio State University, 151 West Woodruff Avenue, Columbus, Ohio 43210, USA

${ }^{2}$ School of Life Science and Biotechnology, Dalian University of Technology, Dalian 116024, China

${ }^{3}$ Bioprocessing Innovative Company, 4734 Bridle Path Ct., Dublin, Ohio 43017, USA

${ }^{4}$ School of Bioscience and Bioengineering, South China University of Technology, Guangzhou 510006, China

*Corresponding author: Phone: 614-2926611; Fax: 614-292-3769; Email: yang.15@osu.edu

Submitted to Metabolic Engineering 


\section{Abstract}

2 Clostridium tyrobutyricum is a promising microorganism for butyric acid production. However, its 3 ability to utilize xylose, the second most abundant sugar found in lignocellulosic biomass, is 4 severely impaired by glucose-mediated carbon catabolite repression (CCR). In this study, CCR in 5 C. tyrobutyricum was eliminated by overexpressing three heterologous xylose catabolism genes 6 ( $x y l T, x y l A$ and $x l y B)$ cloned from $C$. acetobutylicum. Compared to the parental strain, the 7 engineered strain Ct-pTBA produced more butyric acid (37.8 g/L vs. $19.4 \mathrm{~g} / \mathrm{L})$ from glucose and 8 xylose simultaneously, at a higher xylose utilization rate $(1.28 \mathrm{~g} / \mathrm{L} \cdot \mathrm{h}$ vs. $0.16 \mathrm{~g} / \mathrm{L} \cdot \mathrm{h})$ and efficiency 9 (94.3\% vs. $13.8 \%)$, resulting in a higher butyrate productivity $(0.53 \mathrm{~g} / \mathrm{L} \cdot \mathrm{h}$ vs. $0.26 \mathrm{~g} / \mathrm{L} \cdot \mathrm{h})$ and yield $10 \quad(0.32 \mathrm{~g} / \mathrm{g}$ vs. $0.28 \mathrm{~g} / \mathrm{g})$. When the initial total sugar concentration was $\sim 120 \mathrm{~g} / \mathrm{L}$, both glucose and 11 xylose utilization rates increased with increasing their respective concentration or ratio in the 12 co-substrates but the total sugar utilization rate remained almost unchanged in the fermentation at $13 \mathrm{pH}$ 6.0. Decreasing the $\mathrm{pH}$ to 5.0 significantly decreased sugar utilization rates and butyrate 14 productivity, but the effect was more pronounced for xylose than glucose. The addition of benzyl 15 viologen $(\mathrm{BV})$ as an artificial electron carrier facilitated the re-assimilation of acetate and 16 increased butyrate production to a final titer of $46.4 \mathrm{~g} / \mathrm{L}$, yield of $0.43 \mathrm{~g} / \mathrm{g}$ sugar consumed, 17 productivity of $0.87 \mathrm{~g} / \mathrm{L} \cdot \mathrm{h}$, and acid purity of $98.3 \%$ in free-cell batch fermentation, which were the highest ever reported for butyric acid fermentation. The engineered strain with BV addition thus can provide an economical process for butyric acid production from lignocellulosic biomass.

21 Keywords: Butyric acid; Carbon catabolite repression; Clostridium tyrobutyricum; Metabolic 22 engineering; Xylose 


\section{Introduction}

Clostridium tyrobutyricum, a Gram-positive, chemotrophic, spore-forming anaerobe, can produce butyric acid as the main product at a high titer, yield, and productivity from glucose and xylose (Jiang et al., 2010; 2011), two main sugars present in lignocellulosic biomass hydrolysates. C. tyrobutyricum thus has a great potential for industrial production of bio-based butyric acid, which has wide applications in food, animal feed, chemical and pharmaceutical industries (Dwidar et al., 2012; Yang et al., 2013; Zhang et al., 2009) with a global market of >80,000 metric tons per year (Wang et al., 2016). However, like other clostridia, xylose utilization by $C$. tyrobutyricum is inhibited or repressed by glucose, a phenomenon called carbon catabolite repression (CCR) widely observed in bacteria and yeasts (Görke and Stülke, 2008; Yao and Shimizu, 2013; Yu et al., 2015).

Consequently, butyric acid production from lignocellulosic biomass is hindered by the inefficient utilization of xylose in the hydrolysates (Baroi et al., 2015a; 2015b; Liu et al., 2013; Wei et al., 2013; Zhu et al., 2002), which limits its commercial application.

Xylose catabolism in Clostridium usually involves a D-xylose-proton symporter (XylT), xylose isomerase (XylA), and xylulokinase (XylB) (see Figure 1), which are regulated at the transcriptional level by a putative xylose transcriptional repressor XylR and the catabolite control protein A (CcpA) (Gu et al., 2014). XylR could repress $x y l T$, xylA, and $x y l B$ genes (Rodionov et al., 2001), which are present in the same operon in the genome of C. tyrobutyricum ATCC 25755 (Jiang et al., 2013), whereas CcpA is the global transcriptional regulator in CCR (Lorca et al., 2005; Moreno et al., 2004). The enzyme II (GlcG) in the glucose phosphoenolpyruvate (PEP)-dependent phosphotransferase system (PTS) also plays an important role in the induction of CCR (Tangney 
and Mitchell, 2007; Xiao et al., 2011). Previous studies showed that butanol production and xylose utilization in the presence of glucose were greatly enhanced in solventogenic C. acetobutylicum

3 (Xiao et al., 2011) and C. tyrobutyricum (Yu et al., 2015) overexpressing $x y l T$, xylA and $x y l B$,

4 which appeared to be an effective metabolic engineering strategy to eliminate or alleviate the 5 glucose-mediated CCR.

6 The objective of the present study was to engineer C. tyrobutyricum for butyric acid production 7 from both glucose and xylose. Three genes, xylT (CAC1345), xylB (CAC2612), and $x y l A$

8 (CAC2610) from C. acetobutylicum were cloned and overexpressed in C. tyrobutyricum under the 9 control of a thiolase promoter. We hypothesized that constitutively expressing heterologous XylT, $10 \mathrm{XylB}$, and XylA could circumvent the CCR regulated by native XylR and CcpA, thus allowing 11 efficient co-utilization of xylose and glucose, which was confirmed in batch fermentations carried 12 out in serum bottles and bioreactors in this study. The mutant Ct-pTBA overexpressing these three 13 genes was also characterized for its ability to use xylose at various $\mathrm{pH}$ values and glucose/xylose 14 ratios in batch fermentation. Furthermore, we also studied the effects of benzyl viologen (BV) as 15 an artificial electron carrier on increasing NADH availability and butyric acid production from 16 glucose and xylose, and demonstrated that adding a small amount of BV could increase butyric 17 acid production by re-assimilating acetate, achieving a high butyrate yield and purity needed for 18 economic production of bio-based butyric acid. These results indicated that C. tyrobutyricum 19 Ct-pTBA is a promising strain for butyric acid production from abundant, renewable 20 lignocellulosic biomass. 


\section{Materials and methods}

2

3

4

5

6

7

8

9

10

11

12

13

14

15

16

17

18

19

20

\subsection{Cultures and media}

The bacterial strains, plasmids and primers used in this study are listed in Table 1. C. tyrobutyricum strains were cultivated anaerobically at $37^{\circ} \mathrm{C}$ in Clostridial Growth Medium (CGM) described previously (Liu et al., 2006; Zhu et al., 2005). E. coli DH5 $\alpha$ and E. coli CA434 were grown aerobically at $37{ }^{\circ} \mathrm{C}$ with agitation at $250 \mathrm{rpm}$ in Luria-Bertani (LB) media or on LB agar plates. All media were autoclaved $\left(121^{\circ} \mathrm{C}\right.$ for $\left.30 \mathrm{~min}\right)$ and then supplemented with corresponding antibiotics $(30 \mu \mathrm{g} / \mathrm{mL}$ chloramphenicol, $50 \mu \mathrm{g} / \mathrm{mL}$ kanamycin, $30 \mu \mathrm{g} / \mathrm{mL}$ thiamphenicol or 250 $\mu \mathrm{g} / \mathrm{mL}$ cycloserine), unless otherwise noted.

\subsection{Plasmid construction}

Three genes, xylT (CAC1345), xylB (CAC2612), and xylA (CAC2610), in the xylose catabolic pathway from $C$. acetobutylicum ATCC 824 were used in constructing the recombinant plasmid pTBA (see Figure S1 in Supplementary Materials). First, $x y l$ TB and $x y l$ A were separately PCR-amplified from Ct( $\Delta a c k)$-pTBA (Yu et al., 2015) using primers shown in Table 1. To construct the recombinant plasmid pTBA, pMAD22 (Yu et al., 2011) was first digested with $B a m \mathrm{HI}$ and SacII to remove $a d h \mathrm{E} 2$, and then ligated sequentially with $x y l \mathrm{~TB}$ and $x y l \mathrm{~A}$ using the Clontech infusion cloning kit (Clontech Laboratories, Inc., Mountain View, CA). All recombinant plasmids were first transformed into E. coli DH5a for amplification. Plasmids were then extracted using Qiagen QIAprep Mini-Prep plasmid purification kit (Valencia, CA) and confirmed by checking plasmid size and digestion pattern. 


\subsection{Transformation}

The transformation of pTBA into $C$. tyrobutyricum was done by conjugation carried out in an anaerobic chamber following previously described procedures (Yu et al., 2012). First, pTBA was transformed into $E$. coli CA434 cells, which were cultivated in LB medium containing $30 \mu \mathrm{g} / \mathrm{mL}$ chloramphenicol and $50 \mu \mathrm{g} / \mathrm{mL}$ kanamycin at $37{ }^{\circ} \mathrm{C}$ overnight. The E. coli CA434 cells were collected by centrifugation, washed with sterile phosphate-buffered saline (PBS), mixed with $C$. tyrobutyricum $\mathrm{Ct}$ cells, and the mixture was then pipetted onto CGM agar plates. After $12 \mathrm{~h}$, cells were collected with CGM and re-plated on selective CGM plates containing $250 \mu \mathrm{g} / \mathrm{mL}$ cycloserine and $30 \mu \mathrm{g} / \mathrm{mL}$ thiamphenicol. The plates were incubated at $37^{\circ} \mathrm{C}$ until visible colonies were formed. Positive transformants were confirmed by colony PCR and plasmid extraction followed with gel electrophoresis to verify the plasmid size. The selected transformant was maintained in CGM containing $30 \mu \mathrm{g} / \mathrm{mL}$ thiamphenicol and $15 \%$ glycerol, and stored at $-80{ }^{\circ} \mathrm{C}$.

\subsection{Fermentation kinetics studies}

Batch fermentation kinetics with glucose, xylose, and glucose/xylose mixture, respectively, as carbon sources was first studied in serum bottles (50 ml CGM buffered with $40 \mathrm{~g} / \mathrm{L} \mathrm{CaCO}_{3}$ ) and then in 1-L bioreactors (600 ml CGM) with $\mathrm{pH}$ controlled with ammonia hydroxide (30\%, v/v) at $37^{\circ} \mathrm{C}$. The serum bottles and bioreactors were sterilized by autoclaving at $121{ }^{\circ} \mathrm{C}$ for $30 \mathrm{~min}$, sparged with nitrogen for $\sim 30$ min to reach anaerobiosis, and then inoculated with an active seed culture $(\sim 24 \mathrm{~h})$ at a volume ratio of $5 \%$. For Ct-pTBA, $30 \mu \mathrm{g} / \mathrm{mL}$ thiamphenicol was also added into the medium at the time of inoculation. Batch fermentation kinetics was studied with glucose 
and xylose at different ratios and at various $\mathrm{pH}$ values $(6.0,5.5$, and 5.0). The effects of $\mathrm{BV}$ and acetic acid addition on butyric acid production were also studied. Liquid samples were taken at regular time intervals to monitor cell growth, sugar consumption and acid production.

\subsection{Analytical methods}

5 Cell density was monitored by measuring the optical density (OD) at $600 \mathrm{~nm}$ using a spectrophotometer (UV-16-1, Shimadzu, Columbia, MD). Glucose, xylose, acetic acid, lactic acid and butyric acid were analyzed by high performance liquid chromatography (HPLC, LC-20AD, Shimadzu, Columbia, MD) with an organic acid analysis column (HPX-87H, Bio-Rad, Hercules,

$9 \mathrm{CA}$ ) at $65{ }^{\circ} \mathrm{C}$ and $0.005 \mathrm{M}$ sulfuric acid as the mobile phase at $0.6 \mathrm{~mL} / \mathrm{min}$. Details can be found elsewhere (Liu and Yang, 2006).

\section{Results}

\subsection{Batch fermentation of glucose and xylose by Ct and Ct-pTBA}

Batch fermentation of glucose, xylose and glucose/xylose (1:1), respectively, as carbon

14

15

16

17

18

19

20 sources were first evaluated in serum bottles with $40 \mathrm{~g} / \mathrm{L}$ calcium carbonate to buffer the culture $\mathrm{pH}$ at $\sim 5.5$. The results with $C$. tyrobutyricum strains $\mathrm{Ct}$ and Ct-pTBA are summarized in Table 2. In general, both strains could use xylose as the sole carbon source, although xylose fermentation was much slower compared to glucose (see Figure S2 in Supplementary Materials), which could be attributed to the fact that less acetate and ATP were produced from xylose (Zhu and Yang, 2004). Compared to $\mathrm{Ct}, \mathrm{Ct}-\mathrm{pTBA}$ was significantly faster in utilizing xylose (xylose uptake rate: $0.32 \pm$ 0.03 vs. $0.24 \pm 0.03 \mathrm{~g} / \mathrm{L} \cdot \mathrm{h}$ ), but slower in utilizing glucose (glucose uptake rate: $0.46 \pm 0.02$ vs. 
$10.64 \pm 0.02 \mathrm{~g} / \mathrm{L} \cdot \mathrm{h})$. The slower growth on glucose by Ct-pTBA could be attributed to the added

metabolic burden to overexpress XylT, XylA, and XylB. However, when glucose and xylose were both present in the medium, xylose utilization was inhibited in the fermentation with $\mathrm{Ct}$, while simultaneous utilization of xylose and glucose was observed in the fermentation with Ct-pTBA. Apparently, xylose utilization was inhibited in $\mathrm{Ct}$ due to glucose-induced CCR, which was alleviated in Ct-pTBA overexpressing $x y l T, x y l A$, and $x y l B$. It should be noted that xylose was not utilized by $\mathrm{Ct}$ even after all glucose had been consumed in the fermentation. This was probably due to that xylose fermentation was sensitive to the $\mathrm{pH}$ (Zhu and Yang, 2004), which decreased from the initial 6.5 to $\sim 4.8$ in serum bottles and thus stopped the fermentation due to $\mathrm{pH}$ limitation. The effect of overexpressing $x y l T, x y l A$, and $x y l B$ on the fermentation with glucose and xylose as co-substrates was further studied in bioreactor with $\mathrm{pH}$ controlled at 6.0. As shown in Figure $\mathbf{2 A}, \mathrm{Ct}$ consumed all glucose in $38 \mathrm{~h}$ but only $13.8 \%$ of the xylose in $75 \mathrm{~h}$, producing $19.4 \mathrm{~g} / \mathrm{L}$ butyric acid at a low overall productivity of $0.26 \mathrm{~g} / \mathrm{L} \cdot \mathrm{h}$ and yield of $0.28 \mathrm{~g} / \mathrm{g}$. In contrast, Ct-pTBA consumed all glucose and $94.3 \%$ xylose simultaneously and produced $37.8 \mathrm{~g} / \mathrm{L}$ butyric acid in $72 \mathrm{~h}$ (Figure $2 \mathbf{B}$ ), at an overall productivity of $0.53 \mathrm{~g} / \mathrm{L} \cdot \mathrm{h}$ and yield of $0.32 \mathrm{~g} / \mathrm{g}$, which were $104 \%$ and 14\%, respectively, higher than those by Ct. Excluding the periods of the initial lag and late stationary phases, $\mathrm{Ct}$ had a higher butyrate productivity of $0.92 \mathrm{~g} / \mathrm{L} \cdot \mathrm{h}$ from glucose compared to $0.76 \mathrm{~g} / \mathrm{L} \cdot \mathrm{h}$ by $\mathrm{Ct}-\mathrm{pTBA}$ from the mixture of glucose and xylose. Compared to $\mathrm{Ct}$, glucose consumption was slowed down (rate: $1.16 \mathrm{~g} / \mathrm{L} \cdot \mathrm{h}$ vs. $1.60 \mathrm{~g} / \mathrm{L} \cdot \mathrm{h}$ ) while xylose consumption was accelerated (rate: $1.28 \mathrm{~g} / \mathrm{L} \cdot \mathrm{h}$ vs. $0.16 \mathrm{~g} / \mathrm{L} \cdot \mathrm{h}$ ) in Ct-pTBA. Although cell growth seemed to be slower at the beginning for Ct-pTBA, both Ct and Ct-pTBA had a similar specific growth rate of 
$1 \sim 0.14 \pm 0.01 \mathrm{~h}^{-1}$ in the fermentation (see Figure S3A in Supplementary Materials), suggesting that

2 the addition of antibiotic and overexpressing XylT, XylA, and XylB did not negatively impact cell

3 growth in the fermentation by Ct-pTBA.

\section{$4 \quad$ 3.2. Effects of $p H$}

5 Xylose fermentation by C. tyrobutyricum is affected by the $\mathrm{pH}$ (Zhu and Yang, 2004). The

6 effects of $\mathrm{pH}$ on glucose and xylose utilization by Ct-pTBA were thus studied in bioreactor with its

$7 \mathrm{pH}$ controlled at 5.0, 5.5 and 6.0, respectively. About equal amount $(\sim 60 \mathrm{~g} / \mathrm{L})$ of glucose and

8 xylose was used as co-substrates in the fermentation. The fermentation profiles are shown in

$9 \quad$ Figure 3 and corresponding kinetic parameters are summarized in Table 3. At $\mathrm{pH}$ 6.0, the strain consumed glucose and xylose simultaneously, and all glucose and 95\% of xylose were consumed in $74 \mathrm{~h}$, producing $37.8 \mathrm{~g} / \mathrm{L}$ butyric acid at a productivity of $\sim 0.86 \mathrm{~g} / \mathrm{L} \cdot \mathrm{h}$ and yield of $0.32 \mathrm{~g} / \mathrm{g}$. At $\mathrm{pH} 5.5$, all glucose and $66 \%$ of xylose were consumed in $84 \mathrm{~h}$, producing $30.2 \mathrm{~g} / \mathrm{L}$ butyric acid at a productivity of $\sim 0.55 \mathrm{~g} / \mathrm{L} \cdot \mathrm{h}$ and yield of $0.29 \mathrm{~g} / \mathrm{g}$. When the $\mathrm{pH}$ decreased to 5.0 , the fermentation was significantly slower with only $58 \%$ of glucose and $29 \%$ of xylose consumed and $15.6 \mathrm{~g} / \mathrm{L}$ butyric acid produced in $84 \mathrm{~h}$. The much lower rates in consuming glucose $(0.66 \mathrm{~g} / \mathrm{L} \cdot \mathrm{h})$ and xylose $(0.38 \mathrm{~g} / \mathrm{L} \cdot \mathrm{h})$ and in producing butyrate $(0.34 \mathrm{~g} / \mathrm{L} \cdot \mathrm{h})$ at $\mathrm{pH} 5.0$ could be attributed to the cytotoxicity of the undissociated butyric acid $\left(p K_{a}=4.82\right)$ (Wu and Yang, 2003), which inhibited cell growth and metabolism by disrupting the transmembrane $\mathrm{pH}$ gradient and reducing ATP level and activities of acid-forming enzymes (Zhu and Yang, 2003; Zigova and Sturdik, 2000). Our result was in good agreement with the observation of a decreased xylose consumption rate from 
$1 \sim 1.1 \mathrm{~g} / \mathrm{L} \cdot \mathrm{h}$ at $\mathrm{pH} 6.3$ to $\sim 0.56 \mathrm{~g} / \mathrm{L} \cdot \mathrm{h}$ at pH 5.3 in batch fermentation by $C$. tyrobutyricum (Zhu and

2 Yang, 2004). It should be noted that the inhibition seemed to be more pronounced on xylose than

3 on glucose utilization rate. The former reduced $73 \%$ (from $1.40 \mathrm{~g} / \mathrm{L} \cdot \mathrm{h}$ at $\mathrm{pH} 6.0$ to $0.38 \mathrm{~g} / \mathrm{L} \cdot \mathrm{h}$ at

$4 \mathrm{pH} 5.0$ ) while the latter reduced $45 \%$ (from $1.20 \mathrm{~g} / \mathrm{L} \cdot \mathrm{h}$ at $\mathrm{pH} 6.0$ to $0.66 \mathrm{~g} / \mathrm{L} \cdot \mathrm{h}$ at $\mathrm{pH} 5.0$ ). The

5 higher $\mathrm{pH}$ sensitivity for xylose utilization could be attributed to the fact that xylose transport is

6 mainly through the xylose-proton symporter while glucose is via PEP-dependent PTS. The

7 results suggest that $\mathrm{pH}$ control at $\sim 6.0$ is crucial for efficient co-utilization of glucose and xylose

8 by C. tyrobutyricum Ct-pTBA.

9 3.3. Effects of glucose/xylose ratio

The fermentation kinetics of Ct-pTBA with glucose, xylose and mixtures of glucose and

11 xylose at different ratios (3:1, 1:1, and 1:3), representing the sugar compositions found in different

12 lignocellulose hydrolysates, were investigated in bioreactor at $\mathrm{pH} 6.0$ (see Figure 4), and the

13 results are summarized in Table 3. As expected, glucose fermentation (Fig. 4A) was faster than

14 xylose fermentation (Fig. 4B) because glucose metabolism could provide more ATP for cell

15 growth. Consequently, xylose fermentation gave a significantly lower specific growth rate $(0.09$

$16 \mathrm{~h}^{-1}$ vs. $\left.0.16 \mathrm{~h}^{-1}\right)$, sugar utilization rate $(1.78 \mathrm{~g} / \mathrm{L} \cdot \mathrm{h}$ vs. $2.79 \mathrm{~g} / \mathrm{L} \cdot \mathrm{h})$, and butyrate productivity $(0.51$

$17 \mathrm{~g} / \mathrm{L} \cdot \mathrm{h}$ vs. $0.86 \mathrm{~g} / \mathrm{L} \cdot \mathrm{h}$ ) compared to glucose fermentation (see Table 3). However, the final butyric acid titer $(\sim 36.5 \mathrm{~g} / \mathrm{L})$ and yield $(\sim 0.30 \mathrm{~g} / \mathrm{g})$ were comparable for both xylose and glucose as the sole carbon source in the fermentation. 
1 In the fermentations with glucose and xylose as co-substrates, both the specific growth rate and

2 butyrate productivity generally increased with increasing the glucose/xylose ratio (Fig. 4E).

3 Interestingly, both glucose and xylose consumption rates increased with increasing their respective

4 ratio or concentration in the substrate mixture, but the total sugar consumption rate was almost the

5 same at $\sim 2.5 \mathrm{~g} / \mathrm{L} \cdot \mathrm{h}$ for all three glucose/xylose ratios studied. These results suggested that the

6 catabolism of glucose and xylose in Ct-pTBA was limited by the sugar uptake (or influx) rate,

7 which apparently increased with the extracellular sugar concentration. An earlier study also

8 reported that xylose utilization by $C$. thermohydrosulfuricum, which was not subjected to

9 glucose-mediated CCR, increased with xylose concentration $(0-50 \mathrm{mM})$ and suggested that xylose

10 uptake was a facilitated diffusion process (Cook et al., 1993). The increased xylose utilization

11 rate could also be attributed to increased activities of xylose isomerase and xylulose kinase, which

12 in Clostridium sp. strain $\mathrm{BOH} 3$ were found to increase proportionally with the extracellular xylose

13 concentration (Xin et al., 2014). The fact that both glucose and xylose utilization rates increased

14 with increasing their respective concentration also suggested that xylose transport was through

15 both XylT and non-XylT while glucose transport involved both PTS and non-PTS (see Fig. 1),

16 which remains to be verified experimentally, however.

\section{3.4. Effect of benzyl viologen (BV) on butyric acid production}

18 Butyric acid biosynthesis in C. tyrobutyricum requires NADH and is accompanied with acetate

19 biosynthesis, which not only provides ATP needed for cell growth but also balances the redox.

20 Previous studies have shown that the addition of an artificial electron carrier such as methyl 
1 viologen (MV) in the fermentation medium can provide more $\mathrm{NADH}$, via reduced hydrogen

2 production, for the biosynthesis of more reduced metabolites such as butyrate (vs. acetate) and

3 butanol (Choi et al., 2012; Du et al., 2014; Rao and Mutharasan, 1987). Therefore, an artificial

4 electron carrier, BV, was studied for its effects on butyric acid production and sugar utilization in

5 the co-fermentation of glucose and xylose by Ct-pTBA. Because of its inhibition effect on cell

6 growth, BV was added at the late exponential or early stationary phase in the fermentation. As

7 shown in Figure 5, the addition of BV did not seem to affect sugar utilization but induced acetate

8 re-assimilation and increased butyrate production. Compared to the fermentation without BV

9 addition (see Fig. 2B), a significantly higher final butyric acid titer of 39.8 g/L (vs. 37.8 g/L) and yield of $0.36 \mathrm{~g} / \mathrm{g}$ (vs. $0.32 \mathrm{~g} / \mathrm{g}$ ) were obtained in the fermentation with $0.75 \mu \mathrm{M} \mathrm{BV}$ (Fig. 5A). In fact, the butyrate yield from sugars was $0.42 \mathrm{~g} / \mathrm{g}$ after BV addition. The increased butyrate production could be attributed to the re-assimilation of acetic acid, which decreased from $2.74 \mathrm{~g} / \mathrm{L}$ at $38 \mathrm{~h}$ (the time $\mathrm{BV}$ was added) to zero at $70 \mathrm{~h}$. Interestingly, upon the depletion of acetate, lactic acid production started and reached $0.45 \mathrm{~g} / \mathrm{L}$ at the end of the fermentation. The production of lactic acid, which was observed only in the presence of BV and in the absence of acetate, was probably for cells to consume NADH for redox balance. medium verified that acetate re-assimilation occurred without lactate production while butyric acid production increased to $46.4 \mathrm{~g} / \mathrm{L}$ (Fig. 5B). Butyric acid yield from sugars increased from 
$1 \mathrm{~mol} / \mathrm{mol}(0.39 \mathrm{~g} / \mathrm{g})$ when acetate $(0.4 \mathrm{~mol} / \mathrm{mol})$ and carbon dioxide $(2 \mathrm{~mol} / \mathrm{mol})$ are also produced

2 as co-products (Wang et al., 2014; Zhang et al., 2009). In contrast, butyrate formation from

3 acetate has a theoretical yield of $0.73 \mathrm{~g} / \mathrm{g}(0.5 \mathrm{~mol} / \mathrm{mol})$, which is $87.2 \%$ higher than that from

4 glucose, because no substrate carbon is lost in carbon dioxide. In addition to the higher butyrate

5 yield, butyrate was produced as the only main product in the fermentation with a high acid purity

6 of $98.3 \%$, which was not only much higher than $\sim 80 \%$ in typical butyric acid fermentation but also

7 higher than those obtained with metabolically engineered butyrate-producing $C$. acetobutylicum

8 (88\%) (Jang et al., 2014) and E. coli (97.6\%) (Lim et al., 2013). It should be noted that only

$977 \%-84 \%$ of the xylose was consumed while all glucose was utilized in these fermentations. This was because butyric acid inhibition was more pronounced in xylose fermentation than in glucose fermentation (Jiang et al., 2010; Liu and Yang, 2006).

Figure 6 illustrates the metabolic pathways involved in lactate, acetate and butyrate 13 biosynthesis, and possible effects of $\mathrm{BV}$ on metabolic flux distributions among various 14 metabolites and NADH balance. Table 4 shows the carbon balance in the co-fermentation of 15 glucose and xylose (1:1) by $\mathrm{Ct}$ and Ct-pTBA. Ct used glucose as the preferred substrate, accounting for $87.8 \%$ (vs. $12.2 \%$ for xylose) of the carbon consumed in the fermentation. In

17 contrast, Ct-pTBA used both glucose and xylose almost equally at 50\% each. When BV was present, more glucose $(55 \%)$ was consumed as the carbon source than xylose (45\%), because of the increased butyrate production, which inhibited xylose metabolism more. The carbon distributions in the products shifted to more butyrate (from $66.5 \%$ to $73.1 \%$ ) and less acetate (from

$2117.8 \%$ to $0 \%$ ) in the presence of $\mathrm{BV}$. Adding acetate in the fermentation medium further 
1 increased butyrate flux to $\sim 76 \%$, with the remaining substrate carbons mainly in cell biomass and

$2 \mathrm{CO}_{2}$, which was not monitored in this study. Clearly, adding the electronic carrier BV shifted the

3 metabolic flux toward butyric acid biosynthesis, achieving complete butyrate selectivity against

4 acetate with butyrate as the sole acid product in the fermentation. It should be noted that complete

5 butyrate selectivity was also observed in $C$. tyrobutyricum BAS 7 by using a cathodic electron

6 donor to alter NADH formation and flux distribution (Choi et al., 2012). However, only a low

7 butyric acid concentration of $8.8 \mathrm{~g} / \mathrm{L}$ was reached and the complicated electro-bioreactor system

8 would be difficult to scale up for industrial application.

\section{4. Discussion}

Lignocellulosic biomass as a cost-effective feedstock for fermentation to produce chemicals and fuels requires efficient utilization of both glucose and xylose by microorganisms (Cho et al.,

12 2015; Gu et al., 2014; Ho et al., 1998; Jaros et al., 2013; Liu et al., 2013; Wang et al., 2014).

However, when multiple carbon sources are present, the consumption of the preferred carbon

14 source (i.e., glucose) usually prevents the uptake and catabolism of the secondary substrates (e.g.,

15 xylose), a phenomenon called CCR (Görke and Stülke, 2008). The glucose-mediated CCR has

16 also been observed in clostridia, including $C$. acetobutylicum, $C$. beijerinckii, and $C$.

17 tyrobutyricum (Gu et al., 2010; Ounine et al., 1985; Xiao et al., 2012; Yu et al., 2015). To date,

18 various metabolic engineering strategies have been used to address the inefficient xylose

19 utilization problem caused by glucose repression in solventogenic Clostridium, including

20 disrupting the global transcriptional regulator CcpA (Ren et al., 2010; Wu et al., 2015), the putative 
1 xylose transcriptional repressor XylR (Hu et al., 2011; Xiao et al., 2012) and enzyme II in the

2 glucose PTS (Xiao et al., 2011), and overexpressing key genes (tal, tkl, rpi and rpe) in the pentose

3 phosphate pathway (Cu et al., 2009; Jin et al., 2014) and genes ( $x y l T, x y l A$, and $x y l B)$ in the xylose

4 catabolic pathway (Yu et al., 2015). Among them, overexpressing $x y l T, x y l A$, and $x y l B$ was able

5 to greatly increase butanol production from glucose and xylose as co-substrates without CCR or any undesirable effects (Yu et al., 2015). Overexpressing $x y l T$, $x y l A$, and $x y l B$ also enabled Propionibacterium freudenreichii to utilize xylose in the presence of glucose without CCR (Wei et al., 2016). Clearly, the xylose utilization pathway is the prime target for metabolic engineering to overcome the CCR. Although this metabolic engineering strategy has been demonstrated for enhancing butanol and propionic acid production from xylose, it has not been used nor studied for enhancing butyric acid production from xylose previously. alternative xylose isomerase (xylA, CAC2620) and a xylulokinase ( $x y l B$, CAC2612) associated with xylose catabolism in $C$. acetobutylicum (Gu et al., 2010) were co-expressed in $C$. tyrobutyricum. The mutant Ct-pTBA overexpressing these heterologous genes under the control of native thl promoter was able to efficiently co-utilize glucose and xylose for butyric acid usually induced by xylose and repressed by glucose (Gu et al., 2010). However, these regulations 
1 their activities in $C$. tyrobutyricum, thus removing the CCR and enhancing xylose utilization by

2 Ct-pTBA. It is noted, however, that the xylose utilization efficiency or rate increased with

3 increasing the xylose concentration or xylose/glucose ratio and decreased with decreasing the

4 fermentation $\mathrm{pH}$. Similar effects were also observed with glucose utilization, but the $\mathrm{pH}$ effect

5 was less pronounced. This concentration and $\mathrm{pH}$ dependent xylose utilization by clostridia has not

6 been reported previously.

7 Economical production of butyric acid from lignocellulose hydrolysates also requires high

8 final titer, productivity, yield, and purity (Zhu et al., 2002). C. tyrobutyricum produces butyrate

9 concomitantly with acetate, carbon dioxide, and hydrogen (see Fig. 6). Different metabolites are

10 produced to balance redox and provide ATP needed for cell growth and metabolism. In general,

11 attempts to knockout genes (ack and pta) in the acetate biosynthesis pathway failed to eliminate

12 acetate production (Lee et al., 2016; Liu et al., 2006; Zhu et al., 2005). Since metabolic flux

13 distribution is dictated by the available reducing power or NADH (Zhou et al., 2010), various

14 strategies have been used to increase NADH availability for the biosynthesis of the more reduced

15 product butyrate (vs. acetate) in butyric acid fermentation, including inactivating hydrogenase

16 (hydA) (Jang et al., 2014) and adding artificial electron carriers, such as MV, BV and neutral red

17 (NR), to divert the electrons from hydrogen to NADH production (Choi et al., 2012; Du et al.,

18 2014; Rao and Mutharasan, 1987; Reimann et al., 1996; Yu et al., 2015). Choi et al. (2012) showed

19 that MV addition increased intracellular NADH pool by $\sim 3$ times in $C$. tyrobutyricum BAS 7 with

20 greatly reduced hydrogen production and enhanced butyrate yield and selectivity. The main effect

21 of BV or MV addition is thus to increase the amount of NADH produced by the Ferredoxin-NAD ${ }^{+}$ 
reductase (see Tables S1-S3 in Supplemental Materials), as was also previously demonstrated in $C$. acetobutylicum with MV or NR addition (Girbal et al., 1995; Peguin et al., 1994). In the present study, we demonstrated that BV addition at a low concentration of $0.75-3.75 \mu \mathrm{M}$ could effectively shift the flux for acetate from its formation to re-assimilation to butyrate, achieving a complete selectivity for butyrate as the sole acid product from glucose and xylose. Although a high butyrate selectivity could also be accomplished by knocking out competitive NADH-consuming pathways in engineered E. coli (Lim et al., 2013) and C. acetobutylicum (Jang et al., 2014), adding a small amount of BV without knocking out multiple genes in the genome, which often causes unhealthy cell growth and metabolism, is a simple and effective approach that can be easily scaled up for industrial application. It should also be noted that acetate re-assimilation can potentially

11 increase the overall butyrate yield from sugar to $0.73 \mathrm{~g} / \mathrm{g}$ since acetate can be produced at $\sim 100 \%$

12 yield (g/g) from glucose in a homoacetic fermentation (Yang et al., 2013). Furthermore, adding acetate as a co-substrate with sugar also inhibited acetate production and increased butyrate production to a selectivity of $\sim 1.0$, which was also reported recently with an acetate-consuming

15 Clostridium sp. S1 (Kim et al., 2016). However, xylose utilization by Clostridium sp. S1 was 16 partially repressed by glucose due to CCR.

\section{5. Conclusions}

The glucose-mediated CCR was eliminated by overexpressing three heterologous xylose catabolism genes ( $x y l T, x y l A$ and $x l y B)$ in C. tyrobutyricum. The engineered strain Ct-pTBA was capable of producing butyric acid from glucose and xylose simultaneously at high sugar utilization 
rate and efficiency. The addition of $\mathrm{BV}$ as an artificial electron carrier facilitated the re-assimilation of acetate and increased butyrate production to a high final titer of $46.4 \mathrm{~g} / \mathrm{L}$, yield of $0.43 \mathrm{~g} / \mathrm{g}$ sugar consumed, productivity of $0.87 \mathrm{~g} / \mathrm{L} \cdot \mathrm{h}$, and acid purity of $98.3 \%$ in free-cell batch fermentation, which were the highest ever reported for butyric acid fermentation. The engineered strain with BV addition can provide an economical process for butyric acid production from lignocellulosic biomass.

\section{Acknowledgments}

This work was supported in part by the National Science Foundation STTR program (IIP-1026648) and the Ministry of Agriculture 948 project (No. 2014-Z27), China. Financial support to Fu as a visiting scholar at OSU from China Scholarship Council (201306060042) is also acknowledged.

\section{Appendix A. Supplementary material}

\section{References}

Baroi, G. N., Baumann, I., Westermann, P., Gavala, H. N., 2015a. Butyric acid fermentation from pretreated and hydrolysed wheat straw by an adapted Clostridium tyrobutyricum strain. Microb. Biotechnol. $8,874-882$.

Baroi, G. N., Skiadas, I. V., Westermann, P., Gavala, H. N., 2015b. Continuous fermentation of wheat straw hydrolysate by Clostridium tyrobutyricum with in-situ acids removal. Waste. Biomass. Valori. 6, $317-326$.

Cho, C., Jang, Y. S., Moon, H. G., Lee, J., Lee, S. Y., 2015. Metabolic engineering of clostridia for the production of chemicals. Biofuels. Bioprod. Biorefin. 9, 211-225.

Choi, O., Um, Y., Sang, B. I., 2012. Butyrate production enhancement by Clostridium tyrobutyricum using 
electron mediators and a cathodic electron donor. Biotechnol. Bioeng. 109, 2494-2502.

Cook, G. M., Janssen, P. H., Morgan, H. W., 1993. Simultaneous uptake and utilisation of glucose and xylose by Clostridium thermohydrosulfuricum. Fems. Microbiol. Lett. 109, 55-61.

Cu, Y., Li, J., Zhang, L., Chen, J., Niu, L. X., Yang, Y. L., Yang, S., Jiang, W. H., 2009. Improvement of xylose utilization in Clostridium acetobutylicum via expression of the talA gene encoding transaldolase from Escherichia coli. J. Biotechnol. 143, 284-287.

Du, Y., Jiang, W., Yu, M., Tang, I. C., Yang, S. T., 2014. Metabolic process engineering of Clostridium tyrobutyricum $\Delta$ ack-adhE2 for enhanced n-butanol production from glucose: Effects of methyl viologen on NADH availability, flux distribution and fermentation kinetics. Biotechnol. Bioeng. $112,705-715$.

Dwidar, M., Park, J. Y., Mitchell, R. J., Sang, B. I., 2012. The future of butyric acid in industry. Sci. World. J. 2012, 471417.

Girbal, L., Vasconcelos, I., Saint-Amans, S., Soucaille, P., 1995. How neutral red modified carbon and electron flow in Clostridium acetobutylicum grown in chemostat culture at neutral pH. FEMS Microbiol. Rev. 16, 151-162.

Görke, B., Stülke, J., 2008. Carbon catabolite repression in bacteria: many ways to make the most out of nutrients. Nat. Rev. Microbiol. 6, 613-624.

Gu, Y., Ding, Y., Ren, C., Sun, Z., Rodionov, D. A., Zhang, W. W., Yang, S., Yang, C., Jiang, W. H., 2010. Reconstruction of xylose utilization pathway and regulons in Firmicutes. BMC Genomics. 11.

Gu, Y., Jiang, Y., Yang, S., Jiang, W. H., 2014. Utilization of economical substrate-derived carbohydrates by solventogenic clostridia: pathway dissection, regulation and engineering. Curr. Opin. Biotechnol. 29, 124-131.

Heap, J. T., Pennington, O. J., Cartman, S. T., Minton, N. P., 2009. A modular system for Clostridium shuttle plasmids. J. Microbiol. Meth. 78, 79-85.

Ho, N. W. Y., Chen, Z. D., Brainard, A. P., 1998. Genetically engineered Saccharomyces yeast capable of effective cofermentation of glucose and xylose. Appl. Environ. Microb. 64, 1852-1859.

Hu, S., Zheng, H., Gu, Y., Zhao, J., Zhang, W., Yang, Y., Wang, S., Zhao, G., Yang, S., Jiang, W., 
2011. Comparative genomic and transcriptomic analysis revealed genetic characteristics related to solvent formation and xylose utilization in Clostridium acetobutylicum EA 2018. BMC Genomics 12: 93.

Jang, Y. S., Im, J. A., Choi, S. Y., Lee, J. I., Lee, S. Y., 2014. Metabolic engineering of Clostridium acetobutylicum for butyric acid production with high butyric acid selectivity. Metab. Eng. 23, $165-174$.

Jaros, A. M., Rova, U., Berglund, K. A., 2013. Acetate adaptation of Clostridium tyrobutyricum for improved fermentation production of butyrate. SpringerPlus. 2: 47.

Jiang, L., Zhu, L., Xu, X., Li, Y., Li, S., Huang, H., 2013. Genome sequence of Clostridium tyrobutyricum ATCC 25755, a butyric acid-overproducing strain. Genome Announc. 1(3), e00308-13

Jiang, L., Wang, J. F., Liang, S. Z., Cai, J., Xu, Z. N., Cen, P. L., Yang, S. T., Li, S. A., 2011. Enhanced butyric acid tolerance and bioproduction by Clostridium tyrobutyricum immobilized in a fibrous bed bioreactor. Biotechnol. Bioeng. 108, 31-40.

Jiang, L., Wang, J. F., Liang, S. Z., Wang, X. N., Cen, P. L., Xu, Z. N., 2010. Production of butyric acid from glucose and xylose with immobilized cells of Clostridium tyrobutyricum in a fibrous-bed bioreactor. Appl. Biochem. Biotechnol. 160, 350-359.

Jin, L., Zhang, H., Chen, L. W., Yang, C., Yang, S., Jiang, W. H., Gu, Y., 2014. Combined overexpression of genes involved in pentose phosphate pathway enables enhanced D-xylose utilization by Clostridium acetobutylicum. J. Biotechnol. 173, 7-9.

Kim, M, Kim, K.-Y., Lee, K. M., Youn, S. H., Lee, S.-M., Woo, H. M., Oh, M.-K., Um Y., 2016. Butyric acid production from softwood hydrolysate by acetate-consuming Clostridium sp. S1 with high butyric acid yield and selectivity. Bioresour. Technol., 218, 1208-1214.

Lee, J., Jang, Y. S., Han, M. J., Kim, J. Y., Lee, S. Y., 2016. Deciphering Clostridium tyrobutyricum metabolism based on the whole-genome sequence and proteome analyses. mBio 7(3), e00743-16.

Lim, J. H., Seo, S. W., Kim, S. Y., Jung, G. Y., 2013. Refactoring redox cofactor regeneration for high-yield biocatalysis of glucose to butyric acid in Escherichia coli. Bioresource. Technol. 135, 568-573.

Liu, S. Q., Bischoff, K. M., Leathers, T. D., Qureshi, N., Rich, J. O., Hughes, S. R., 2013. Butyric acid from 
anaerobic fermentation of lignocellulosic biomass hydrolysates by Clostridium tyrobutyricum strain RPT-4213. Bioresource. Technol. 143, 322-329.

Liu, X. G, Zhu, Y., Yang, S. T., 2006. Construction and characterization of ack deleted mutant of Clostridium tyrobutyricum for enhanced butyric acid and hydrogen production. Biotechnol. Progr. $22,1265-1275$.

Liu, X. G., Yang, S. T., 2006. Kinetics of butyric acid fermentation of glucose and xylose by Clostridium tyrobutyricum wild type and mutant. Process. Biochem. 41, 801-808.

Lorca, G.L., Chung, Y.J., Barabote, R.D., Weyler, W., Schilling, C.H., Saier, M.H. Jr., 2005. Catabolite repression and activation in Bacillus subtilis: dependency on CcpA, HPr, and HprK. J. Bacteriol. $187,7826-7839$.

Moreno, M.S., Schneider, B.L., Maile, R.R., Weyler, W., Saier, M.H. Jr., 2001. Catabolite repression mediated by the CcpA protein in Bacillus subtilis: novel modes of regulation revealed by whole-genome analyses. Mol. Microbiol. 39, 1366-1381.

Ounine, K., Petitdemange, H., Raval, G., Gay, R., 1985. Regulation and butanol inhibition of D-xylose and D-glucose uptake in Clostridium acetobutylicum. Appl. Environ. Microbiol. 49, 874-878.

Peguin, S., Goma, S., Delorme, P., Soucaille, P., 1994. Metabolic flexibility of Clostridium acetobutylicum in response to methyl viologen. Appl. Microbiol. Biotechnol. 42, 611-616.

Rao, G., Mutharasan, R., 1987. Altered electron flow in continuous cultures of Clostridium acetobutylicum induced by viologen dyes. Appl. Environ. Microb. 53, 1232-1235.

Reimann, A., Biebl, H., Deckwer, W. D., 1996. Influence of iron, phosphate and methyl viologen on glycerol fermentation of Clostridium butyricum. Appl. Microbiol. Biot. 45, 47-50.

Ren, C., Gu, Y., Hu, S. Y., Wu, Y., Wang, P., Yang, Y. L., Yang, C., Yang, S., Jiang, W. H., 2010. Identification and inactivation of pleiotropic regulator CcpA to eliminate glucose repression of xylose utilization in Clostridium acetobutylicum. Metab. Eng. 12, 446-454.

Rodionov, D.A., Mironov, A.A., Gelfand, M.S., 2001. Transcriptional regulation of pentose utilisation systems in the Bacillus/Clostridium group of bacteria. FEMS Microbiol. Lett .205, 305-314.

Tangney, M., Mitchell, W.J., 2007. Characterization of a glucose phosphotransferase system in Clostridium 
acetobutylicum ATCC 824. Appl. Microbiol. Biotechnol., 74, 398-405.

Wang, J. F., Lin, M., Xu, M. M., Yang, S. T., 2016. Anaerobic fermentation for production of carboxylic acids as bulk chemicals from renewable biomass. Adv. Biochem. Eng. Biotechnol. in press, DOI: $10.1007 / 1020155009$.

Wang, J. F., Yang, X. R., Chen, C. C., Yang, S. T., 2014. Engineering clostridia for butanol production from biorenewable resources: from cells to process integration. Curr. Opin. Chem. Eng. 6, 43-54.

Wei, D., Liu, X. G., Yang, S. T., 2013. Butyric acid production from sugarcane bagasse hydrolysate by Clostridium tyrobutyricum immobilized in a fibrous-bed bioreactor. Bioresource. Technol. 129, $553-560$.

Wei, P., Lin, M., Wang, Z., Fu, H., Yang, H., Jiang, W., Yang, S.T., 2016. Metabolic engineering of Propionibacterium freudenreichii subsp. shermanii for xylose fermentation, Bioresour. Technol., 219, 91-97.

Williams, D. R., Young, D. I., Young, M., 1990. Conjugative plasmid transfer from Escherichia coli to Clostridium acetobutylicum. J. Gen. Microbiol. 136, 819-826.

Wu, Z., Yang, S. T., 2003. Extractive fermentation for butyric acid production from glucose by Clostridium tyrobutyricum, Biotechnol. Bioeng., 82, 93-102.

Wu, Y., Yang, Y. P., Ren, C., Yang, C., Yang, S., Gu, Y., Jiang, W. H., 2015. Molecular modulation of pleiotropic regulator CcpA for glucose and xylose coutilization by solvent-producing Clostridium acetobutylicum. Metab. Eng. 28, 169-179.

Xiao, H., Gu, Y., Ning, Y. Y., Yang, Y. L., Mitchell, W. J., Jiang, W. H., Yang, S., 2011. Confirmation and elimination of xylose metabolism bottlenecks in glucose phosphoenolpyruvate-dependent phosphotransferase system-deficient Clostridium acetobutylicum for simultaneous utilization of glucose, xylose, and arabinose. Appl. Environ. Microb. 77, 7886-7895.

Xiao, H., Li, Z. L., Jiang, Y., Yang, Y. L., Jiang, W. H., Gu, Y., Yang, S., 2012. Metabolic engineering of D-xylose pathway in Clostridium beijerinckii to optimize solvent production from xylose mother liquid. Metab. Eng. 14, 569-578.

Xin, F. X., Wu, Y. R., He, J. Z., 2014. Simultaneous fermentation of glucose and xylose to butanol by 
Clostridium sp Strain BOH3. Appl. Environ. Microb. 80, 4771-4778.

Yang, S. T., Yu, M., Chang, W. L, Tang, I. C., 2013. Anaerobic fermentations for the production of acetic and butyric acids, in Yang, S. T., Elnshasy, H. A., Thongchul, N. (eds) Bioprocessing Technologies in Biorefinery for Sustainable Production of Fuels, Chemicals, and Polymers, Wiley: Hoboken, NJ, $351-373$

Yao, R., Shimizu, K., 2013. Recent progress in metabolic engineering for the production of biofuels and biochemicals from renewable sources with particular emphasis on catabolite regulation and its modulation. Process Biochem. 48, 1409-1417.

Yu, L., Xu, M. M., Tang, I. C., Yang, S. T., 2015. Metabolic engineering of Clostridium tyrobutyricum for n-butanol production through co-utilization of glucose and xylose. Biotechnol. Bioeng. 112, 2134-2141.

Yu, M., Du. Y., Jiang, W. Y., Chang W. L., Yang S. T., Tang I. C., 2012. Effects of different replicons in conjugative plasmids on transformation efficiency, plasmid stability, gene expression and n-butanol biosynthesis in Clostridium tyrobutyricum. Appl. Microbiol. Biotechnol. 93, 881-889.

Yu, M., Zhang, Y., Tang, I. C., Yang, S. T., 2011. Metabolic engineering of Clostridium tyrobutyricum for n-butanol production. Metab. Eng. 13, 373-382.

Zhang, C. H., Yang, H., Yang, F. X., Ma, Y. J., 2009. Current progress on butyric acid production by fermentation. Curr. Microbiol. 59, 656-663.

Zhou, S. D., Iverson, A. G., Grayburn, W. S., 2010. Doubling the catabolic reducing power (NADH) output of Escherichia coli fermentation for production of reduced products. Biotechnol. Progr. 26, 45-51.

Zhu, Y., Liu, X. G., Yang, S. T., 2005. Construction and characterization of pta gene-deleted mutant of Clostridium tyrobutyricum for enhanced butyric acid fermentation. Biotechnol. Bioeng. 90, 154-166.

Zhu, Y., Wu, Z. T., Yang, S. T., 2002. Butyric acid production from acid hydrolysate of corn fibre by Clostridium tyrobutyricum in a fibrous-bed bioreactor. Process Biochem. 38, 657-666.

Zhu, Y., Yang, S. T., 2003. Adaptation of Clostridium tyrobutyricum for enhanced tolerance to butyric acid in a fibrous-bed bioreactor, Biotechnol. Progress 19, 365-372. 
1 Zhu, Y., Yang, S. T., 2004. Effect of $\mathrm{pH}$ on metabolic pathway shift in fermentation of xylose by Clostridium tyrobutyricum. J. Biotechnol. 110, 143-157.

3 Zigova, J., Sturdik, E., 2000. Advances in biotechnological production of butyric acid. J. Ind. Microbiol. Biot. 24, 153-160. 


\section{Table 1}

Strains, plasmids and primers used in this study.

\begin{tabular}{|c|c|c|}
\hline Strain/Plasmid & Description & Source \\
\hline \multicolumn{3}{|l|}{ Strains } \\
\hline E. coli $\mathrm{DH} 5 \alpha$ & Host cells for plasmids amplification & Invitrogen \\
\hline E. coli CA434 & Donor cells for conjugation transformation & Williams et al., 1990 \\
\hline $\mathrm{Ct}$ & C. tyrobutyricum ATCC 25755 & Liu et al., 2006 \\
\hline $\mathrm{Ct}(\Delta a c k)-\mathrm{pTBA}$ & $a d h E 2$ and $x y l T B A$ overexpression in $\mathrm{Ct}(\Delta a c k)$ & Yu et al., 2015 \\
\hline Ct-pTBA & Ct overexpressing $x y l T B A$ & This study \\
\hline \multicolumn{3}{|l|}{ Plasmid } \\
\hline pMTL82151 & ColE1 ori; $\mathrm{Cm}^{\mathrm{R}}$; pBP1 ori, TraJ & Heap et al., 2009 \\
\hline pMAD22 & From pMTL82151; P-thl::adhE2 & Yu et al., 2011 \\
\hline pTBA & From pMTL82151; P-thl::xylTBA & This study \\
\hline Primers & \multicolumn{2}{|l|}{ Sequence $\left(5^{\prime}-3{ }^{\prime}\right)$} \\
\hline XylTB-for & \multicolumn{2}{|c|}{ ATTTAAATTTGGATCC AGATTGAGGAGGAATATAAAATGAATAA } \\
\hline XylTB-rev & \multicolumn{2}{|c|}{ AAACAGCTATGACCGAGCTCGCGCTCCTACTTTTAACTATTTATATATCT } \\
\hline XylA-for & \multicolumn{2}{|c|}{ AAAAGTAGGAGCGCGAGGAGGAATTAAAATGAATAATACACCAA } \\
\hline XylA-rev & \multicolumn{2}{|c|}{ AAACAGCTATGACCGCCGCGGATTACTCAAAAGGATTTTCTGTTTT } \\
\hline
\end{tabular}




\section{Table 2}

Fermentation kinetics of Ct and Ct-pTBA in CGM using glucose, xylose and glucose/xylose mixture (1:1) as substrates in serum bottles with $40 \mathrm{~g} / \mathrm{L} \mathrm{CaCO}_{3}$

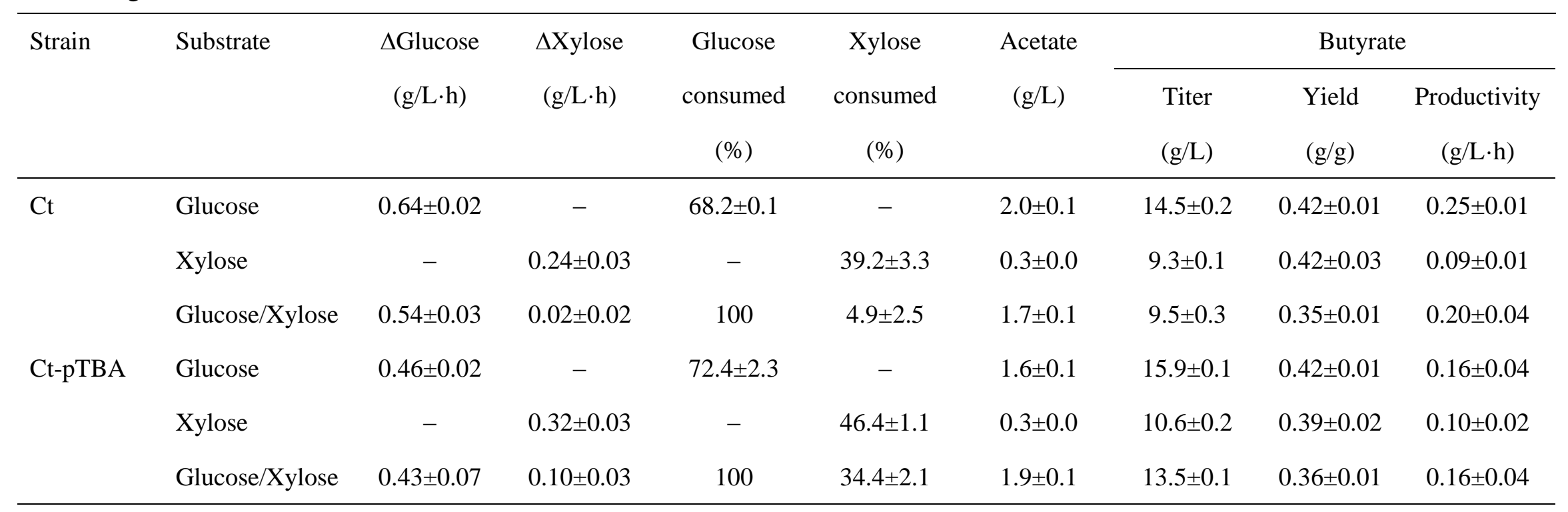

$\Delta$ Glucose: Glucose consumption rate; $\Delta$ Xylose: Xylose consumption rate 


\section{Table 3}

Fermentation kinetics of Ct-pTBA grown on glucose, xylose and glucose/xylose mixtures in bioreactor

\begin{tabular}{|c|c|c|c|c|c|c|c|c|c|c|}
\hline \multirow{2}{*}{$\begin{array}{c}\text { Glucose:Xylose } \\
\text { ratio }(\mathrm{g} / \mathrm{g})\end{array}$} & \multirow[t]{2}{*}{$\mathrm{pH}$} & \multirow{2}{*}{$\begin{array}{c}\mu \\
\left(\mathrm{h}^{-1}\right)\end{array}$} & \multirow{2}{*}{$\begin{array}{c}\Delta \text { Glucose } \\
(\mathrm{g} / \mathrm{L} \cdot \mathrm{h})\end{array}$} & \multirow{2}{*}{$\begin{array}{c}\Delta \text { Xylose } \\
(\mathrm{g} / \mathrm{L} \cdot \mathrm{h})\end{array}$} & \multirow{2}{*}{$\begin{array}{c}\text { Glucose } \\
\text { consumed } \\
(\%)\end{array}$} & \multirow{2}{*}{$\begin{array}{c}\text { Xylose } \\
\text { consumed } \\
(\%)\end{array}$} & \multirow{2}{*}{$\begin{array}{l}\text { Acetate } \\
(\mathrm{g} / \mathrm{L})\end{array}$} & \multicolumn{3}{|c|}{ Butyrate } \\
\hline & & & & & & & & $\begin{array}{l}\text { Titer } \\
(\mathrm{g} / \mathrm{L})\end{array}$ & $\begin{array}{l}\text { Yield } \\
(\mathrm{g} / \mathrm{g})\end{array}$ & $\begin{array}{c}\text { Productivity } \\
\qquad(\mathrm{g} / \mathrm{L} \cdot \mathrm{h})\end{array}$ \\
\hline $1: 0$ & 6.0 & $0.16 \pm 0.01$ & $2.79 \pm 0.20$ & - & 100 & - & $8.0 \pm 0.4$ & $36.5 \pm 0.3$ & $0.30 \pm 0.02$ & $0.86 \pm 0.06$ \\
\hline $0: 1$ & 6.0 & $0.09 \pm 0.01$ & - & $1.78 \pm 0.08$ & - & $91 \pm 1$ & $5.9 \pm 0.4$ & $36.2 \pm 0.2$ & $0.30 \pm 0.02$ & $0.51 \pm 0.05$ \\
\hline $1: 3$ & 6.0 & $0.11 \pm 0.01$ & $0.60 \pm 0.05$ & $1.80 \pm 0.12$ & 100 & $96 \pm 0$ & $8.2 \pm 0.5$ & $39.4 \pm 0.4$ & $0.30 \pm 0.02$ & $0.65 \pm 0.06$ \\
\hline $3: 1$ & 6.0 & $0.14 \pm 0.01$ & $1.80 \pm 0.16$ & $0.73 \pm 0.06$ & 100 & $95 \pm 2$ & $8.7 \pm 0.5$ & $37.4 \pm 0.4$ & $0.32 \pm 0.02$ & $0.84 \pm 0.06$ \\
\hline $1: 1$ & 5.0 & $0.14 \pm 0.01$ & $0.66 \pm 0.02$ & $0.38 \pm 0.02$ & $58 \pm 1$ & $29 \pm 1$ & $5.3 \pm 0.5$ & $15.6 \pm 0.4$ & $0.29 \pm 0.01$ & $0.34 \pm 0.03$ \\
\hline $1: 1$ & 5.5 & $0.14 \pm 0.01$ & $1.11 \pm 0.03$ & $0.97 \pm 0.01$ & 100 & $66 \pm 2$ & $8.7 \pm 0.3$ & $30.2 \pm 0.4$ & $0.29 \pm 0.01$ & $0.55 \pm 0.04$ \\
\hline $1: 1$ & 6.0 & $0.14 \pm 0.01$ & $1.20 \pm 0.04$ & $1.40 \pm 0.12$ & 100 & $94 \pm 1$ & $8.6 \pm 0.6$ & $37.8 \pm 0.4$ & $0.32 \pm 0.02$ & $0.86 \pm 0.10$ \\
\hline \multirow[t]{2}{*}{$1: 1$} & 6.0 & $0.13 \pm 0.01$ & $1.16 \pm 0.05$ & $1.14 \pm 0.11$ & 100 & $84 \pm 1$ & 0 & $39.8 \pm 0.4$ & $0.36 \pm 0.02 *$ & $0.75 \pm 0.10$ \\
\hline & $(\mathrm{BV} 0.75)$ & & & & & & & & $0.42 \pm 0.01^{+}$ & \\
\hline \multirow[t]{2}{*}{$1: 1$} & 6.0 & $0.13 \pm 0.01$ & $1.27 \pm 0.05$ & $0.86 \pm 0.10$ & 100 & $77 \pm 1$ & $0.8 \pm 0.1$ & $46.4 \pm 0.4$ & $0.43 \pm 0.02 *$ & $0.87 \pm 0.10$ \\
\hline & (BV3.75) & & & & & & & & $0.52 \pm 0.01^{+}$ & \\
\hline
\end{tabular}

$\mu$ : Specific growth rate; $\Delta$ Glucose: Glucose consumption rate; $\Delta$ Xylose: Xylose consumption rate

* Overall yield for the entire batch fermentation

${ }^{+}$Butyrate yield for the period with BV addition 


\section{Table 4}

Effects of benzyl viologen on flux distributions and carbon balances on substrate utilization, acetate re-assimilation and product formation in batch fermentations of Ct-pTBA grown on glucose and xylose at pH 6.0

\begin{tabular}{lcccccc}
\hline & \multicolumn{3}{c}{ Substrates } & \multicolumn{2}{c}{ Products } \\
\cline { 2 - 6 } & Glucose $(\%)$ & Xylose $(\%)$ & Acetate $(\%)$ & Butyrate $(\%)$ & Acetate $(\%)$ & Lactate $(\%)$ \\
\hline Ct & $87.8 \pm 1.3$ & $12.2 \pm 1.3$ & 0 & $56.7 \pm 0.2$ & $28.7 \pm 1.0$ & 0 \\
Ct-pTBA & $50.0 \pm 0.7$ & $50.0 \pm 0.7$ & 0 & $66.5 \pm 0.5$ & $17.8 \pm 0.7$ & 0 \\
Ct-pTBA, BV $0.75 \mu \mathrm{M}$ & $55.0 \pm 2.2$ & $45.0 \pm 2.2$ & 0 & $73.1 \pm 0.7$ & $0.9 \pm 0.2$ \\
Ct-pTBA, BV 3.75 $\mu \mathrm{M}$ & $48.3 \pm 1.3$ & $37.6 \pm 0.9$ & $14.1 \pm 0.4$ & $76.0 \pm 1.5$ & $2.1 \pm 0.3$ & 0 \\
\hline
\end{tabular}

Glucose:Xylose ratio in the medium was 1:1. Carbon balance is normalized with the initial total moles of substrate carbon as $100 \%$. 


\section{List of Figures}

Figure 1. Glucose and xylose catabolism in C. tyrobutyricum. Xylose catabolism is repressed by glucose via a putative xylose transcriptional repressor XylR and the catabolite control protein A (CcpA). Genes in the pathway: $x y l T$, D-xylose-proton symporter; xylA, xylose isomerase; $x y l B, \quad x y l u l o k i n a s e ; ~ t a l, \quad$ transaldolase; $t k l$, transketolase; $r p i$, ribose-5-phosphate isomerase; rpe, ribulose-5-phosphate 3-epimerase; glcG, Enzyme II of the D-glucose phosphoenolpyruvate-dependent phosphotransferase system (PTS).

Figure 2. Fermentation kinetics of $C$. tyrobutyricum $\mathrm{Ct}$ and Ct-pTBA in CGM using glucose/xylose mixture (1:1) as substrates at $\mathrm{pH} 6.0$ in bioreactor. Each fermentation condition was repeated at least twice and typical fermentation kinetics is shown here.

Figure 3. Fermentation kinetics of $C$. tyrobutyricum Ct-pTBA in CGM using glucose/xylose mixture (1:1) as substrates at various $\mathrm{pH}$ values in bioreactor. Each fermentation condition was repeated at least twice and typical fermentation kinetics is shown here.

Figure 4. Fermentation kinetics of $C$. tyrobutyricum Ct-pTBA in CGM using glucose, xylose, and glucose/xylose mixture (3:1 and 1:3), respectively, as carbon sources at $\mathrm{pH} 6.0$ in bioreactor. Each fermentation condition was repeated at least twice and typical fermentation kinetics is shown here.

Figure 5. Fermentation kinetics of $C$. tyrobutyricum Ct-pTBA in CGM with glucose/xylose mixture $(1: 1)$ as substrates and $\mathrm{BV}$ as an artificial electron carrier at $\mathrm{pH} 6.0$ in bioreactor. (A) $0.75 \mu \mathrm{M} \mathrm{BV}$ added at $\sim 37 \mathrm{~h}$; (B) $3.75 \mu \mathrm{M} \mathrm{BV}$ with $18 \mathrm{~g} / \mathrm{L}$ acetate added at $\sim 48 \mathrm{~h}$. Each fermentation condition was repeated at least twice and typical fermentation kinetics is shown here.

Figure 6. Metabolic pathways for butyrate, acetate, lactate and hydrogen production from glucose and xylose in C. tyrobutyricum. Butyrate biosynthesis is mainly via a CoA transferase (CoAT), which transfers the CoA from butyryl-CoA to acetate. Benzyl viologen (BV) can divert electrons from hydrogen production to NADH generation, which enhances 
butyrate biosynthesis and acetate re-assimilation, and may cause lactate accumulation (indicated in red dashed line) due to excessive NADH accumulation. Enzymes involved in the pathway: lactate dehydrogenase (LDH), hydrogenase (HydA), phosphotransacetylase (PTA), acetate kinase (AK), phosphotransbutyrylase (PTB), butyrate kinase (BK), CoA transferase (CoAT). 


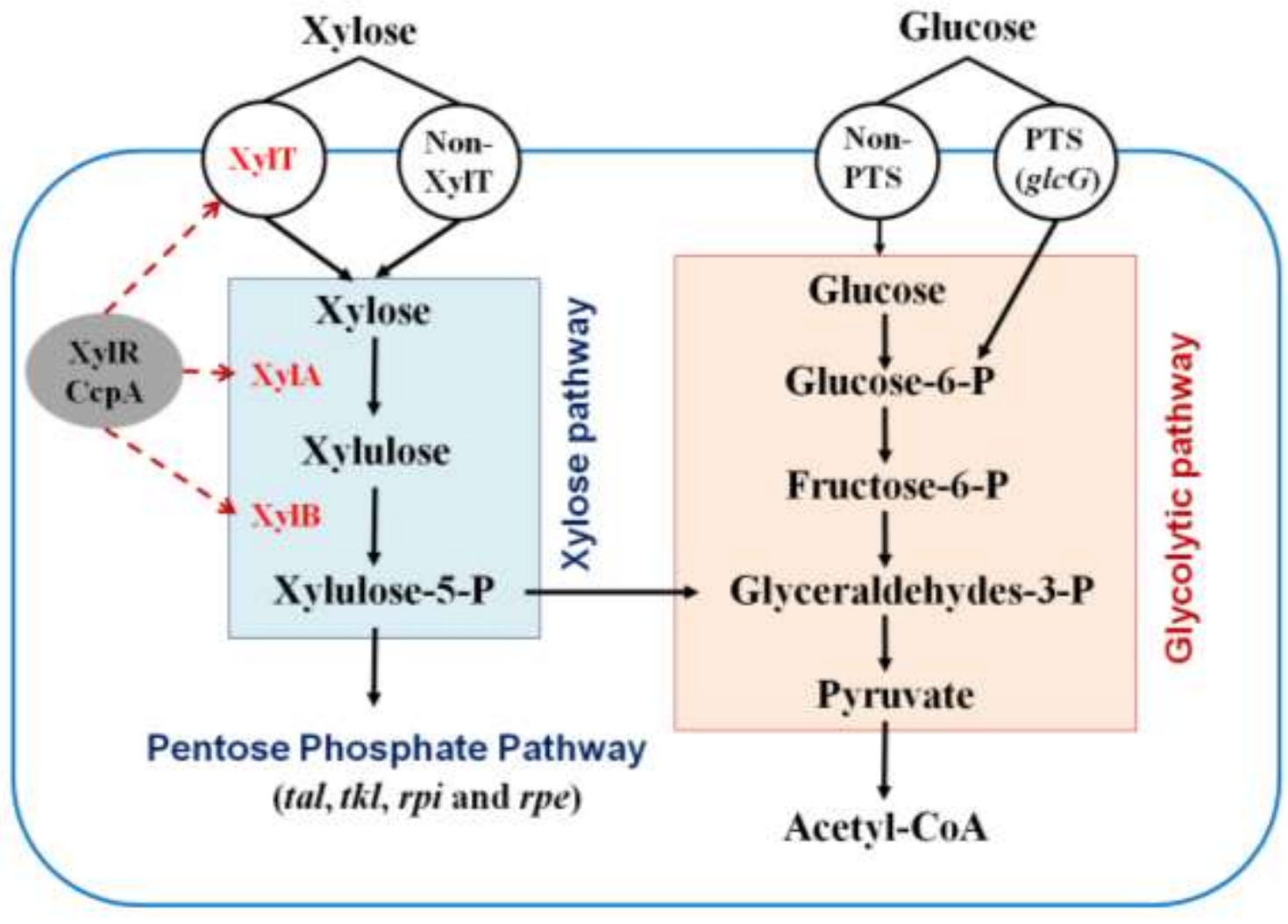

Figure 1 


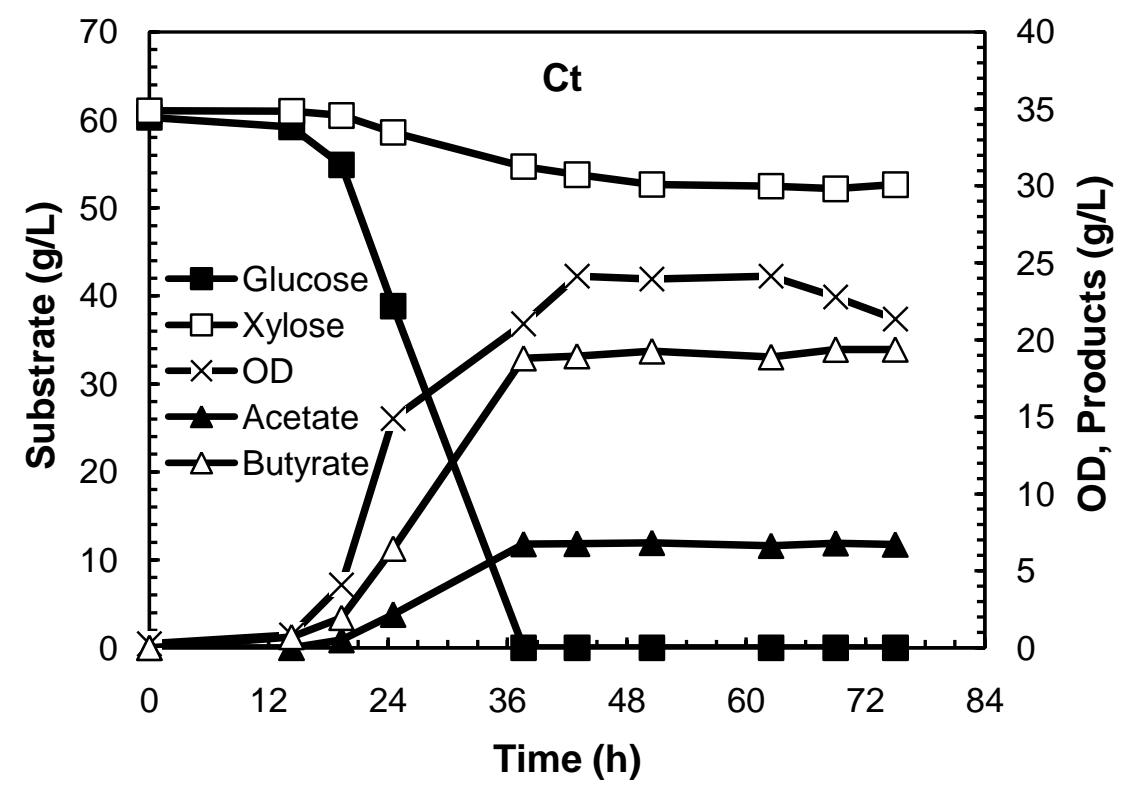

A

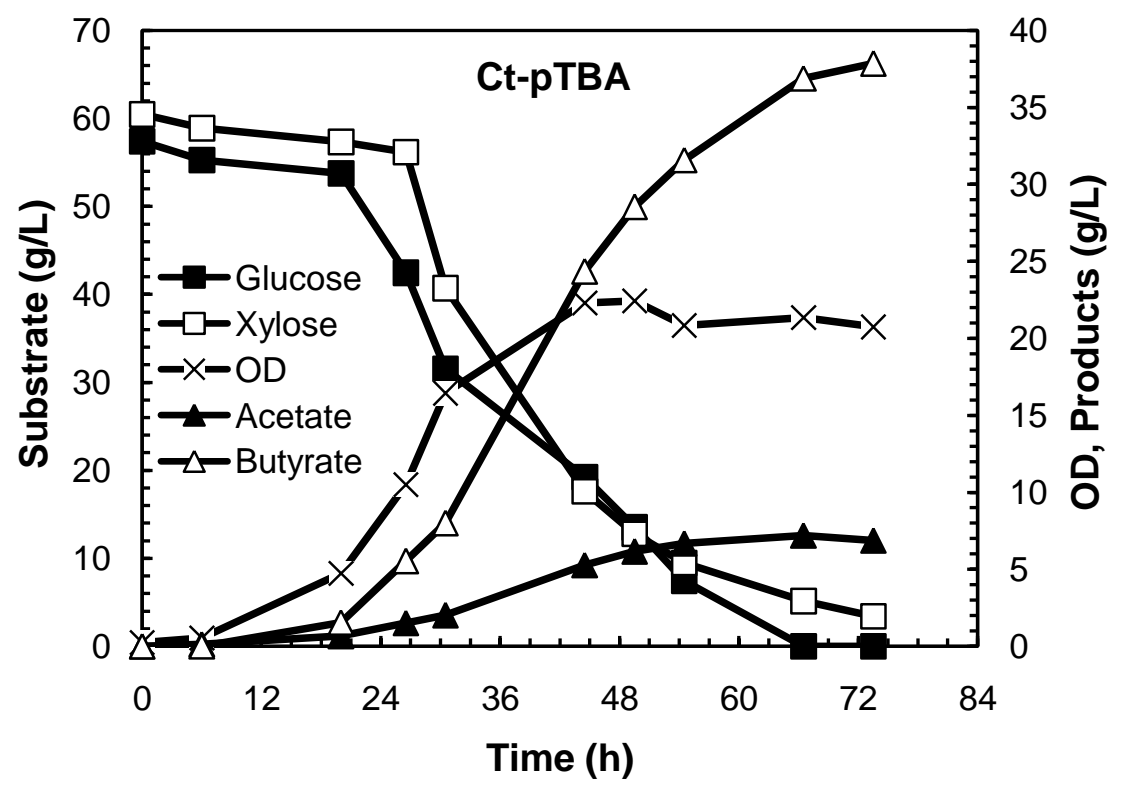

Figure 2 


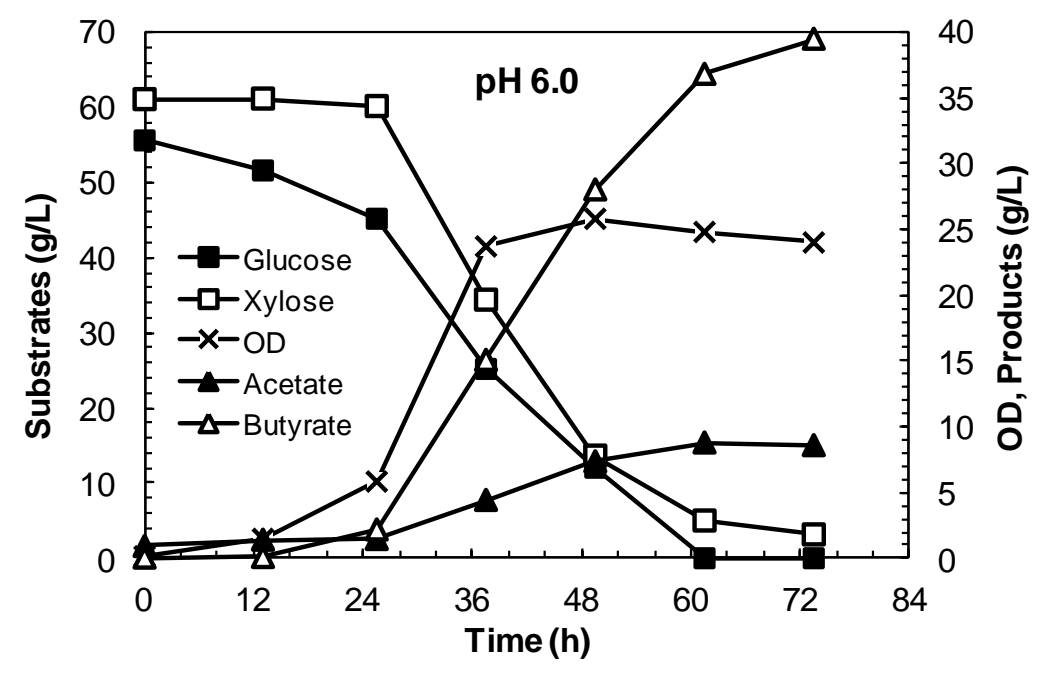

A
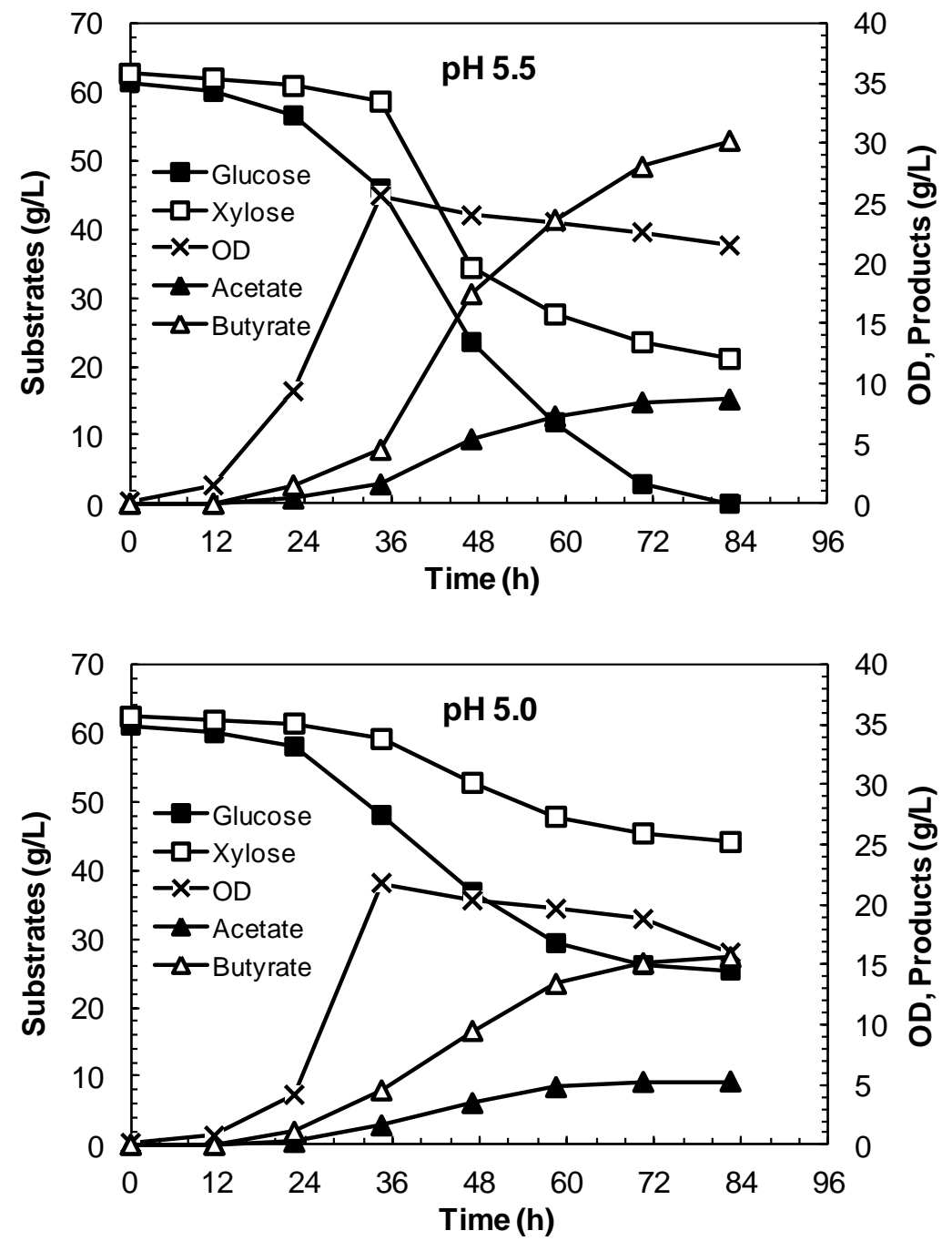

Figure 3 

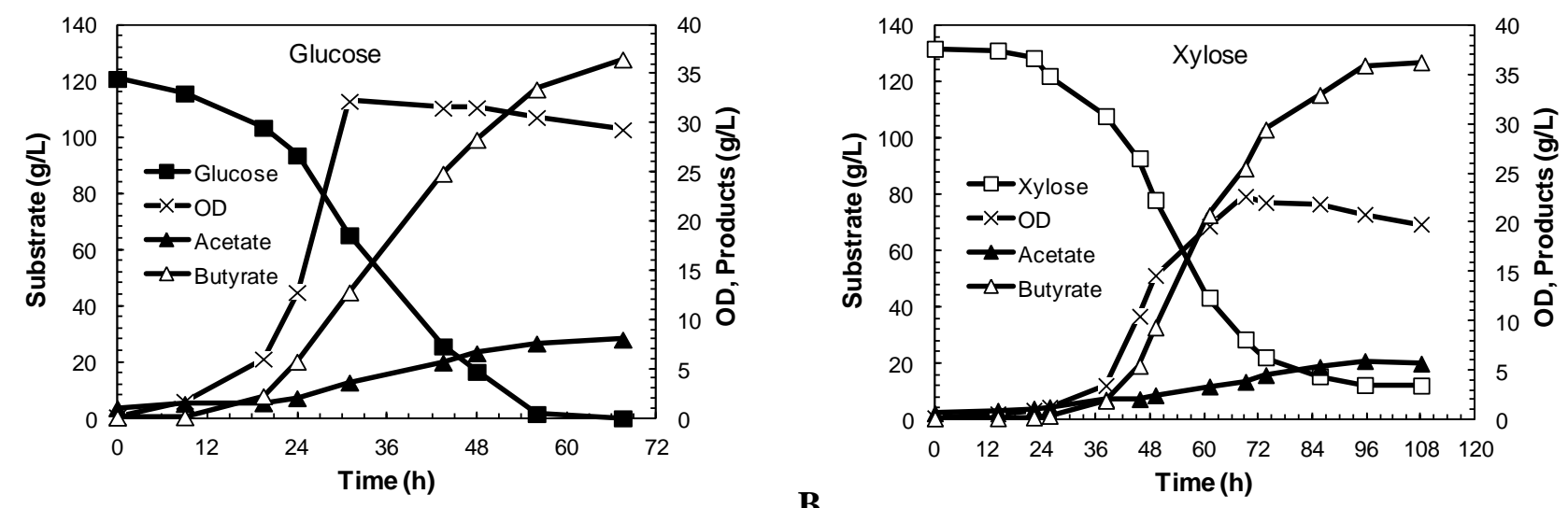

A

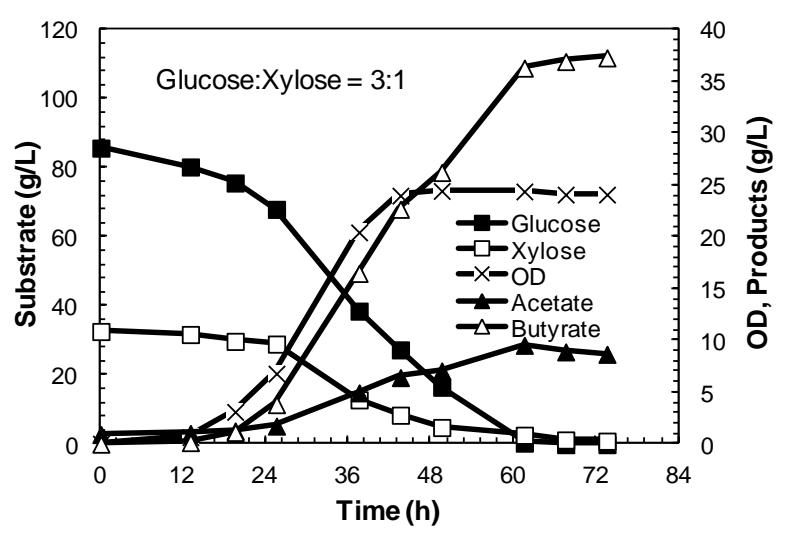

B

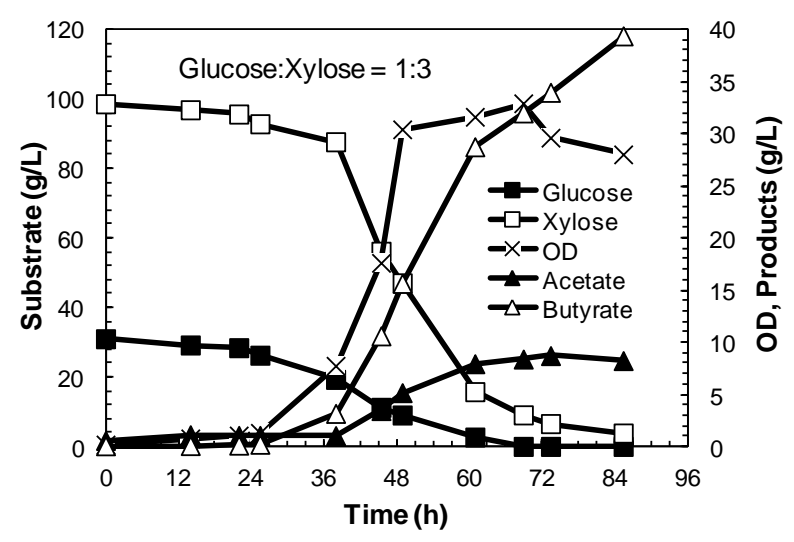

D

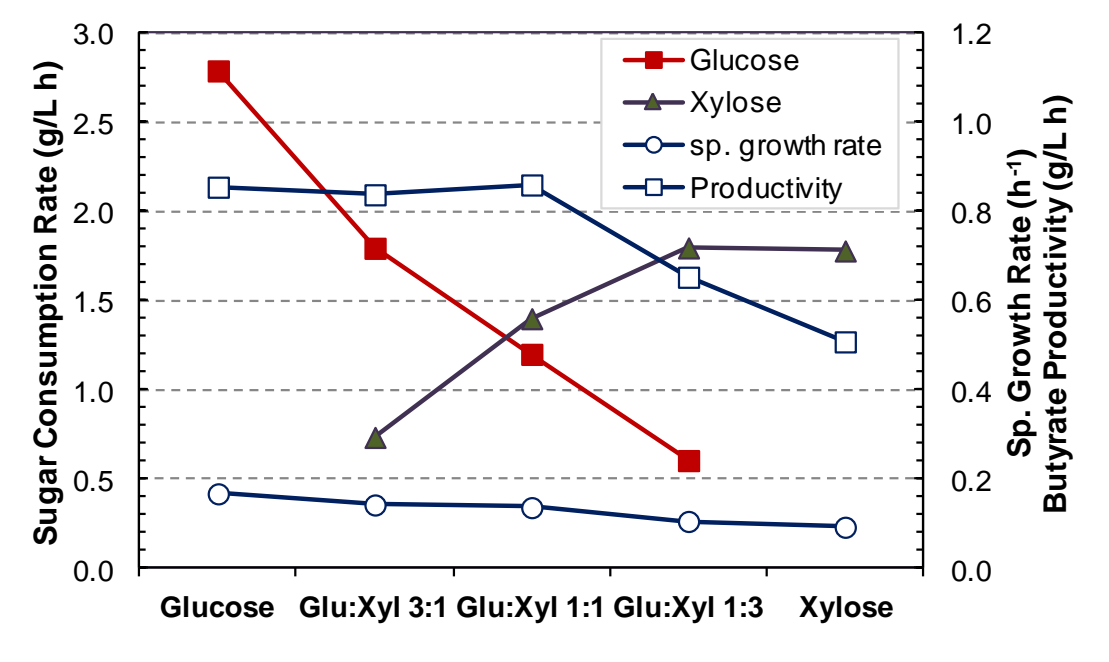

Figure 4 


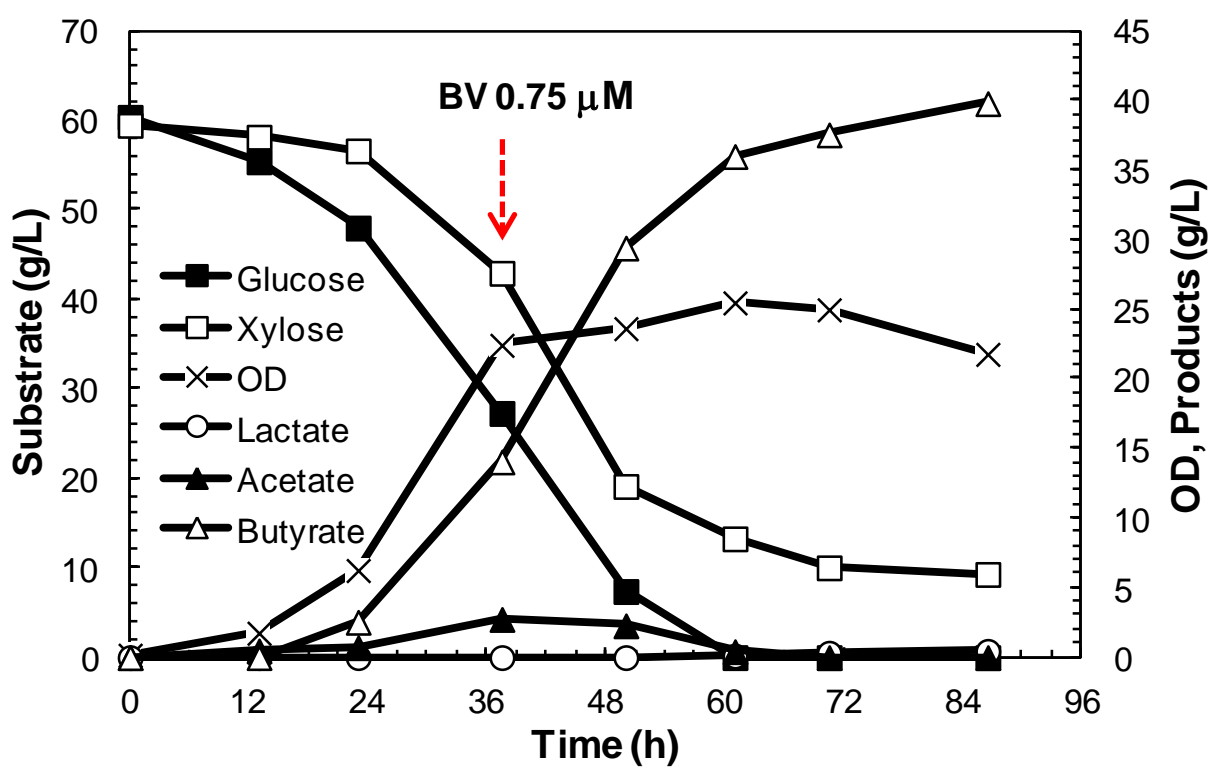

A

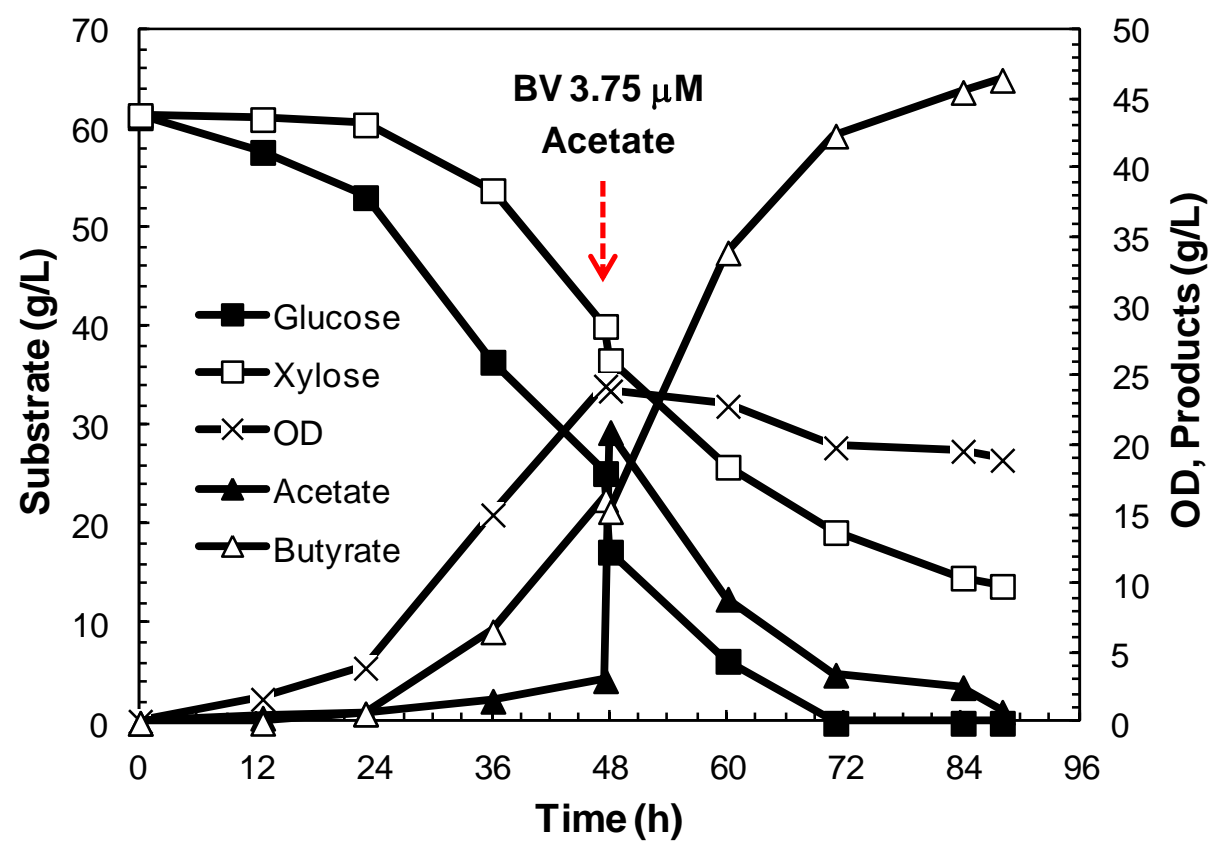

Figure 5 


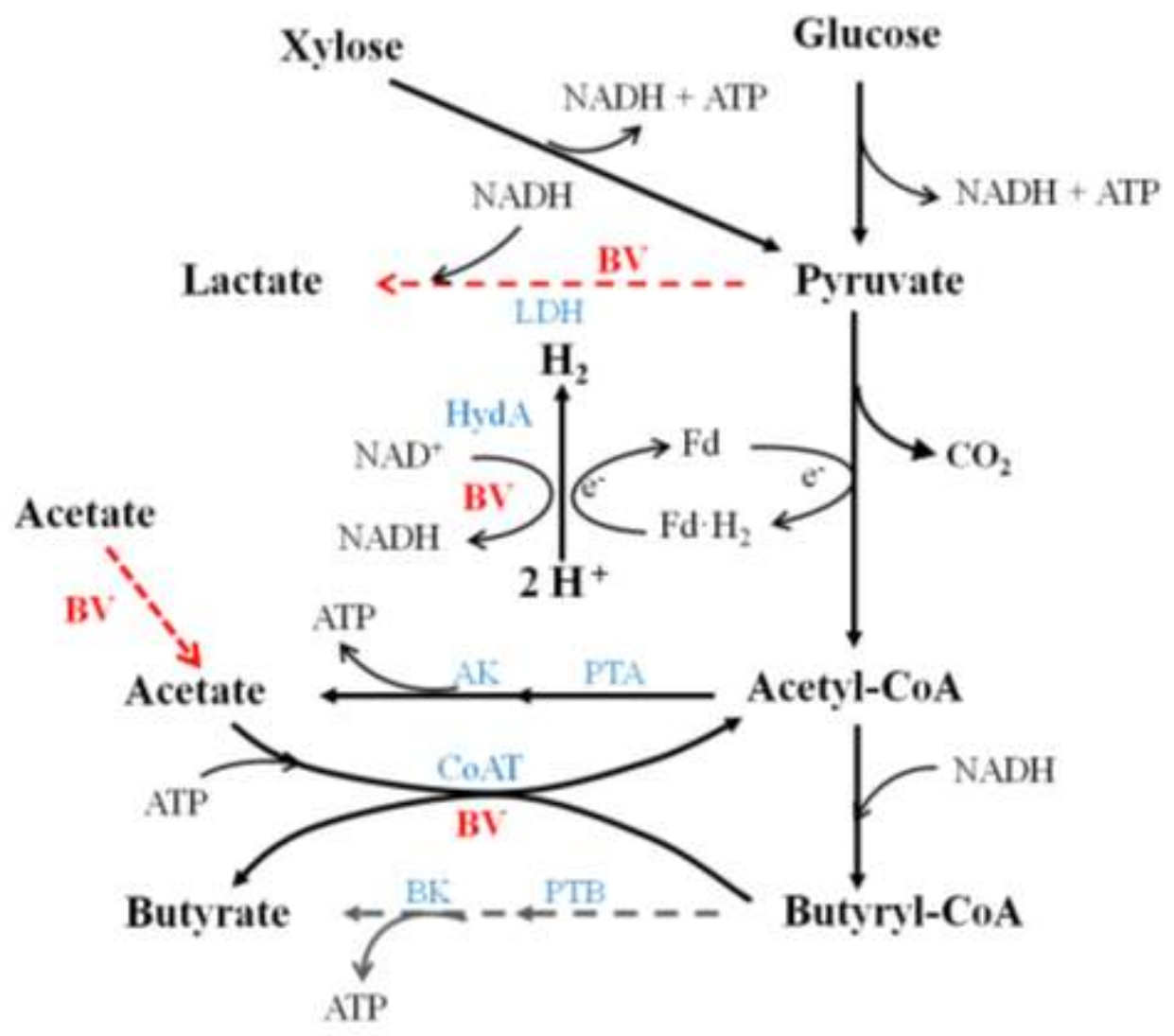

Figure 6 